\title{
Vibrational and Rotational Spectral Data for Possible Interstellar Detection of $\mathrm{AlH}_{3} \mathrm{OH}_{2}, \mathrm{SiH}_{3} \mathrm{OH}$, and $\mathrm{SiH}_{3} \mathrm{NH}_{2}$
}

\author{
A. G. Watrous, ${ }^{1}$ B. R. Westbrook, ${ }^{1}$ M. C. Davis ${ }^{1}$ and Ryan C. Fortenberry ${ }^{1 \star}$ \\ ${ }^{1}$ Department of Chemistry \& Biochemistry, University of Mississippi, University, MS 38677-1848, US
}

Accepted XXX. Received YYY; in original form ZZZ

\section{ABSTRACT}

This work provides the first full set of vibrational and rotational spectral data needed to aid in the detection of $\mathrm{AlH}_{3} \mathrm{OH}_{2}$, $\mathrm{SiH}_{3} \mathrm{OH}$, and $\mathrm{SiH}_{3} \mathrm{NH}_{2}$ in astrophysical or simulated laboratory environments through the use of quantum chemical computations at the CCSD(T)-F12b level of theory employing quartic force fields for the three molecules of interest. Previous work has shown that $\mathrm{SiH}_{3} \mathrm{OH}$ and $\mathrm{SiH}_{3} \mathrm{NH}_{2}$ contain some of the strongest bonds of the most abundant elements in space. $\mathrm{AlH}_{3} \mathrm{OH}_{2}$ also contains highly abundant atoms and represents an intermediate along the reaction pathway from $\mathrm{H}_{2} \mathrm{O}$ and $\mathrm{AlH}_{3}$ to $\mathrm{AlH}_{2} \mathrm{OH}$. All three of these molecules are also polar with $\mathrm{AlH}_{3} \mathrm{OH}_{2}$ having the largest dipole of $4.58 \mathrm{D}$ and the other two having dipole moments in the 1.10-1.30 D range, large enough to allow for the detection of these molecules in space through rotational spectroscopy. The molecules also have substantial infrared intensities with many of the frequencies being over $90 \mathrm{~km} \mathrm{~mol}^{-1}$ and falling within the currently uncertain 12-17 $\mu \mathrm{m}$ region of the spectrum. The most intense frequency for $\mathrm{AlH}_{3} \mathrm{OH}_{2}$ is $v_{9}$ which has an intensity of $412 \mathrm{~km} \mathrm{~mol}^{-1}$ at $777.0 \mathrm{~cm}^{-1}(12.87 \mu \mathrm{m}) . \mathrm{SiH}_{3} \mathrm{OH}$ has an intensity of $183 \mathrm{~km} \mathrm{~mol}^{-1}$ at $1007.8 \mathrm{~cm}^{-1}(9.92 \mu \mathrm{m})$ for $v_{5}$, and $\mathrm{SiH}_{3} \mathrm{NH}_{2}$ has an intensity of $215 \mathrm{~km} \mathrm{~mol}^{-1}$ at $1000.0 \mathrm{~cm}^{-1}(10.00 \mu \mathrm{m})$ for $v_{7}$.

Key words: astrochemistry - molecular data - molecular processes - ISM: molecules - infrared: ISM - radio lines: ISM

\section{INTRODUCTION}

Extraterrestrial Al-O bonds have been found in the form of $\mathrm{AlOH}$ and $\mathrm{AlO}$ in evolved stars and in the atmosphere of the exoplanet WASP43b (Tenenbaum \& Ziurys 2009, 2010; Takigawa et al. 2017; Chubb et al. 2020). Additionally, silicon monoxide ( $\mathrm{SiO}$ ) has been found in Sagittarius B2 (Wilson et al. 1971), but the astronomical literature has not reported any other small molecule detections containing an Si-O bond (McGuire et al. 2018). However, crystalline compounds containing silicon and oxygen, such as enstatite $\left(\mathrm{MgSiO}_{3}\right)$, have been spectroscopically observed toward NGC 6302 (Molster et al. 2001, 2002) with most of the spectral data falling in the range of 17-50 $\mu \mathrm{m}$. In contrast, the $2.4-12 \mu \mathrm{m}$ range of the spectrum is mostly attributed to carbon molecules such as polycyclic aromatic hydrocarbons (PAHs) (Molster et al. 2001). Despite the typical attribution of this region to carbonaceous PAHs, there are still many unknowns in the observed spectra that may be filled by other Si containing molecules. In particular, spectral data has many peaks from 12-17 $\mu \mathrm{m}$ that correspond to unknown molecules, but this "uncertain part of the spectra" (Molster et al. 2001) is in the range of many vibrational features for known Si structures (Molster et al. 2001, 2002). Hence, other Si containing molecules may yet be observed in that region. Additionally, oxygen rich stars do not have nearly as strong of PAH features allowing for Si containing molecules with strong vibrational features to be detected there (Molster et al. 2002).

Past work on inorganic oxides and related hydrides, including

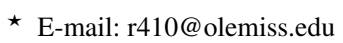

$(\mathrm{MO})_{2}$ with $\mathrm{M}=\mathrm{Al}$ and $\mathrm{Si}$, have been found to have anharmonic frequencies below $20 \mu \mathrm{m}\left(500 \mathrm{~cm}^{-1}\right)$ (Westbrook \& Fortenberry 2020). Most of the M-O bond frequencies fall within the range of the unclear area of IR spectra, and the metal oxides have intensities of over $50 \mathrm{~km} \mathrm{~mol}^{-1}$ for about half of the frequencies. Due to the number of frequencies in a small range within this region, the intensities of the frequencies need to be relatively strong to stand out from the forest of lines. Additionally, the metal oxides and related hydrides previously mentioned have similar features to large, crystalline forms of $\mathrm{Si}$ containing molecules such as enstatite and forsterite $\left(\mathrm{Mg}_{2} \mathrm{SiO}_{4}\right)$, both of which have been detected in space (Molster et al. 2001, 2002). Enstatite and forsterite monomers have also been reported to exhibit infrared intensities over $200 \mathrm{~km} \mathrm{~mol}^{-1}$ which is a large enough intensity for the frequencies of these molecules to stand out from the spectral features of other molecules (Valencia et al. 2020). Consequently, this is a promising spectral region in which to look for other silicon containing molecules.

Previous work has also shown that oxygen and nitrogen form bonds with aluminum and silicon that are stronger than nearly any others in the first three rows of the periodic table (Doerksen \& Fortenberry 2020). Of these aforementioned strong bonds, aluminum and oxygen form the strongest bond followed by silicon and oxygen. As such, $\mathrm{AlH}_{2} \mathrm{OH}$ and $\mathrm{AlH}_{2} \mathrm{NH}_{2}$ have been previously studied computationally and have shown promise for interstellar detection due to their large dipole moments and intense vibrational frequencies (Watrous et al. 2021). Additionally, a previously computed exothermic pathway has shown that $\mathrm{H}_{2} \mathrm{O}$ reacts with a simple aluminum hydride $\left(\mathrm{AlH}_{3}\right)$ molecule to produce $\mathrm{AlH}_{2} \mathrm{OH}$ which could easily form in 
atmospheres of massive stars. This is due to the abundance of water (McGuire et al. 2018) and the perceived presence of $\mathrm{AlH}_{3}$ which is likely unobserved because of its lack of a permanent dipole moment (Swinnen et al. 2009). $\mathrm{AlH}_{3} \mathrm{OH}_{2}$ has been previously computed to be an intermediate formed barrierlessly along this reaction pathway and has an energy lower than the starting reactants (Swinnen et al. 2009). For $\mathrm{AlH}_{3} \mathrm{OH}_{2}$ to persist on its own instead of serving as a short-lived intermediate, it will have to dissipate the excess energy from its formation by emission in the infrared. Such emission will make the infrared spectral data provided herein invaluable for a potential astronomical detection. Regardless, if this molecule is found in space, then $\mathrm{AlH}_{3}$ and $\mathrm{H}_{2} \mathrm{O}$ would also likely be present in the gas phase, allowing the detection of $\mathrm{AlH}_{3} \mathrm{OH}_{2}$ to provide evidence for the presence of the otherwise difficult-to-observe $\mathrm{AlH}_{3}$ molecule. $\mathrm{SiH}_{3} \mathrm{OH}$ and $\mathrm{SiH}_{3} \mathrm{NH}_{2}$ are related molecules of interest given the chemical similarity of $\mathrm{Si}$ and $\mathrm{Al}$ and the strength of bonds between $\mathrm{Si}$ and $\mathrm{N}$ or O. Not only does silicon form strong bonds with oxygen (Doerksen \& Fortenberry 2020), but it also is the third most abundant element in the earth's mantle after oxygen and magnesium, making it a potential component in the formation of planets from dust grains.

To that end, this work utilizes quantum chemical methods to compute optimized structures, energies, and spectroscopic data for $\mathrm{AlH}_{3} \mathrm{OH}_{2}, \mathrm{SiH}_{3} \mathrm{OH}$, and $\mathrm{SiH}_{3} \mathrm{NH}_{2}$. The latter two containing $\mathrm{Si}$ have relatively strong bonds of at least $-91.10 \mathrm{kcal} \mathrm{mol}^{-1}$ (Doerksen \& Fortenberry 2020), and all three contain highly abundant atoms (Savage \& Sembach 1996). The Al-O bond in $\mathrm{AlH}_{3} \mathrm{OH}_{2}$ is dative in nature but still has an energy of more than $17 \mathrm{kcal} \mathrm{mol}^{-1}$ (Swinnen et al. 2009) making it usable with the present methods. None of the three molecules has yet been detected in space, and neither $\mathrm{AlH}_{3} \mathrm{OH}_{2}$ nor $\mathrm{SiH}_{3} \mathrm{OH}$ have been examined experimentally via gas-phase infrared spectroscopy in the laboratory. On the other hand, $\mathrm{SiH}_{3} \mathrm{NH}_{2}$ has been previously observed in the infrared (Beach 1992), offering some gas-phase experimental data to benchmark the present computational work. However, there are still holes in the spectral interpretation that remain to be elucidated.

Theoretical spectral data can be provided at a reasonable balance between accuracy and computational cost by quartic force fields (QFFs), which are a fourth-order Taylor series expansions of the internuclear potential term of the Watson Hamiltonian (Fortenberry \& Lee 2019). QFFs based on coupled cluster theory at the singles, doubles, and perturbative triples level within the explicitly correlated F12b construction [CCSD(T)-F12b] and with the corresponding ccpVTZ-F12 basis set (Raghavachari et al. 1989; Shavitt \& Bartlett 2009; Crawford \& Schaefer III 2000; Peterson et al. 2008; Yousaf \& Peterson 2008) typically produce fundamental vibrational frequencies within 5 to $7 \mathrm{~cm}^{-1}$ of gas-phase experiments (Agbaglo \& Fortenberry 2019a,b). This level of accuracy is sufficient enough to lend theoretical support to NASA missions such as the Stratospheric Observatory for Infrared Astronomy (SOFIA) or the upcoming James Webb Space Telescope (JWST).

\section{COMPUTATIONAL DETAILS}

The geometry optimizations, harmonic frequencies, single point energies, and dipole moments are computed using the Molpro 2015.1 (Werner et al. 2015) and Molpro 2020.1 software packages (Werner et al. 2020) at the CCSD(T)-F12b/cc-pVTZ-F12 (Adler et al. 2007; Peterson et al. 2008; Yousaf \& Peterson 2008; Knizia et al. 2009) level of theory. This will be referred to as F12-TZ. The MP2/aug-cc-pVTZ double-harmonic intensities are computed using the Gaussian 16 program (Møller \& Plesset 1934; Frisch et al. 2016; Kendall et al. 1992).

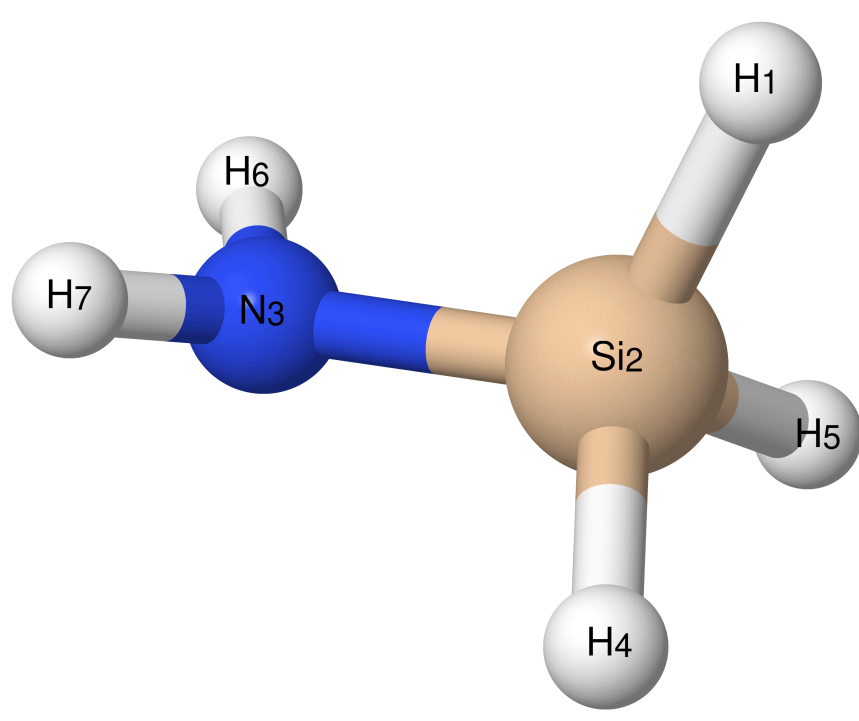

Figure 1. Visual depiction of the $\mathrm{SiH}_{3} \mathrm{NH}_{2}$ structure

Each molecular geometry is first optimized at the F12-TZ level of theory. This geometry is then displaced by $0.005 \AA$ or 0.005 radians along the symmetry-internal coordinates to form the QFFs.

The QFF for $\mathrm{SiH}_{3} \mathrm{NH}_{2}$ is composed of 19585 points and is defined by the coordinate system below, with atom labels corresponding to Figure 1.

$$
\begin{array}{lr}
S_{1}\left(a^{\prime}\right)= & r\left(\mathrm{H}_{1}-\mathrm{Si}_{2}\right) \\
S_{2}\left(a^{\prime}\right)= & (1) \\
\end{array}
$$

$S_{3}\left(a^{\prime}\right)=$ $\frac{1}{\sqrt{2}}\left[r\left(\mathrm{Si}_{2}-\mathrm{H}_{4}\right)+r\left(\mathrm{Si}_{2}-\mathrm{H}_{5}\right)\right]$

$S_{4}\left(a^{\prime}\right)=$ $\frac{1}{\sqrt{2}}\left[r\left(\mathrm{~N}_{3}-\mathrm{H}_{6}\right)+r\left(\mathrm{~N}_{3}-\mathrm{H}_{7}\right)\right]$

$S_{5}\left(a^{\prime}\right)=$ $\angle\left(\mathrm{H}_{1}-\mathrm{Si}_{2}-\mathrm{N}_{3}\right)$

$S_{6}\left(a^{\prime}\right)=$ $\frac{1}{\sqrt{2}}\left[\angle\left(\mathrm{H}_{5}-\mathrm{Si}_{2}-\mathrm{N}_{3}\right)+\angle\left(\mathrm{H}_{4}-\mathrm{Si}_{2}-\mathrm{N}_{3}\right)\right]$

$S_{7}\left(a^{\prime}\right)=$ $\frac{1}{\sqrt{2}}\left[\angle\left(\mathrm{H}_{6}-\mathrm{N}_{3}-\mathrm{Si}_{2}\right)+\angle\left(\mathrm{H}_{7}-\mathrm{N}_{3}-\mathrm{Si}_{2}\right)\right]$

$S_{8}\left(a^{\prime}\right)=\frac{1}{\sqrt{2}}\left[\tau\left(\mathrm{H}_{1}-\mathrm{Si}_{2}-\mathrm{N}_{3}-\mathrm{H}_{6}\right)-\tau\left(\mathrm{H}_{1}-\mathrm{Si}_{2}-\mathrm{N}_{3}-\mathrm{H}_{7}\right)\right]$

$S_{9}\left(a^{\prime}\right)=\frac{1}{\sqrt{2}}\left[\tau\left(\mathrm{H}_{5}-\mathrm{Si}_{2}-\mathrm{N}_{3}-\mathrm{H}_{6}\right)-\tau\left(\mathrm{H}_{4}-\mathrm{Si}_{2}-\mathrm{N}_{3}-\mathrm{H}_{7}\right)\right]$

$S_{10}\left(a^{\prime \prime}\right)=$ $\frac{1}{\sqrt{2}}\left[r\left(\mathrm{Si}_{2}-\mathrm{H}_{4}\right)-r\left(\mathrm{Si}_{2}-\mathrm{H}_{5}\right)\right]$ 


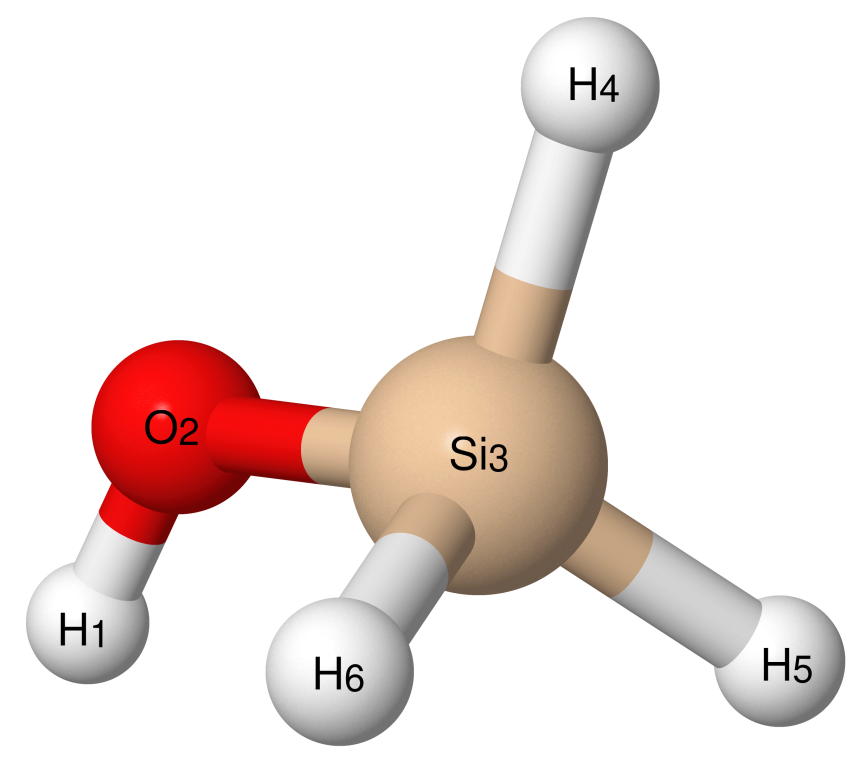

Figure 2. $\mathrm{SiH}_{3} \mathrm{OH}$

$$
S_{11}\left(a^{\prime \prime}\right)=\quad \frac{1}{\sqrt{2}}\left[r\left(\mathrm{~N}_{3}-\mathrm{H}_{6}\right)-r\left(\mathrm{~N}_{3}-\mathrm{H}_{7}\right)\right]
$$

$$
S_{12}\left(a^{\prime \prime}\right)=\quad \frac{1}{\sqrt{2}}\left[\angle\left(\mathrm{H}_{5}-\mathrm{Si}_{2}-\mathrm{N}_{3}\right)-\angle\left(\mathrm{H}_{4}-\mathrm{Si}_{2}-\mathrm{N}_{3}\right)\right]
$$

$$
S_{13}\left(a^{\prime \prime}\right)=\quad \frac{1}{\sqrt{2}}\left[\angle\left(\mathrm{H}_{6}-\mathrm{N}_{3}-\mathrm{Si}_{2}\right)-\angle\left(\mathrm{H}_{7}-\mathrm{N}_{3}-\mathrm{Si}_{2}\right)\right]
$$

$$
S_{14}\left(a^{\prime \prime}\right)=\frac{1}{\sqrt{2}}\left[\tau\left(\mathrm{H}_{1}-\mathrm{Si}_{2}-\mathrm{N}_{3}-\mathrm{H}_{6}\right)+\tau\left(\mathrm{H}_{1}-\mathrm{Si}_{2}-\mathrm{N}_{3}-\mathrm{H}_{7}\right)\right]
$$

$$
S_{15}\left(a^{\prime \prime}\right)=\frac{1}{\sqrt{2}}\left[\tau\left(\mathrm{H}_{5}-\mathrm{Si}_{2}-\mathrm{N}_{3}-\mathrm{H}_{6}\right)+\tau\left(\mathrm{H}_{4}-\mathrm{Si}_{2}-\mathrm{N}_{3}-\mathrm{H}_{7}\right)\right]
$$

The coordinate system for $\mathrm{AlH}_{3} \mathrm{OH}_{2}$ is the same as $\mathrm{SiH}_{3} \mathrm{NH}_{2}$ above with $\mathrm{Al}$ in the place of $\mathrm{Si}$ and $\mathrm{O}$ in the place of $\mathrm{N}$.

The coordinate system for $\mathrm{SiH}_{3} \mathrm{OH}$ requires 8481 points and is defined in the following with atom labels corresponding to Figure 2.

$$
S_{1}\left(a^{\prime}\right)=\quad r\left(\mathrm{H}_{1}-\mathrm{O}_{2}\right)
$$

$S_{2}\left(a^{\prime}\right)=\quad r\left(\mathrm{O}_{2}-\mathrm{Si}_{3}\right)$

$S_{3}\left(a^{\prime}\right)=$

$r\left(\mathrm{Si}_{3}-\mathrm{H}_{4}\right)$

$S_{4}\left(a^{\prime}\right)=\quad \frac{1}{\sqrt{2}}\left[r\left(\mathrm{Si}_{3}-\mathrm{H}_{5}\right)+r\left(\mathrm{Si}_{3}-\mathrm{H}_{6}\right)\right]$

$S_{5}\left(a^{\prime}\right)=\quad \angle\left(\mathrm{H}_{1}-\mathrm{O}_{2}-\mathrm{Si}_{3}\right)$

$S_{6}\left(a^{\prime}\right)=\quad \angle\left(\mathrm{O}_{2}-\mathrm{Si}_{3}-\mathrm{H}_{4}\right)$

$S_{7}\left(a^{\prime}\right)=\quad \frac{1}{\sqrt{2}}\left[\angle\left(\mathrm{O}_{2}-\mathrm{Si}_{3}-\mathrm{H}_{5}\right)+\angle\left(\mathrm{O}_{2}-\mathrm{Si}_{3}-\mathrm{H}_{6}\right)\right]$

$S_{8}\left(a^{\prime}\right)=\frac{1}{\sqrt{2}}\left[\tau\left(\mathrm{H}_{1}-\mathrm{O}_{2}-\mathrm{Si}_{3}-\mathrm{H}_{5}\right)-\tau\left(\mathrm{H}_{1}-\mathrm{O}_{2}-\mathrm{Si}_{3}-\mathrm{H}_{6}\right)\right]$

$$
S_{9}\left(a^{\prime \prime}\right)=\quad \frac{1}{\sqrt{2}}\left[r\left(\mathrm{Si}_{3}-\mathrm{H}_{5}\right)-r\left(\mathrm{Si}_{3}-\mathrm{H}_{6}\right)\right]
$$

$S_{10}\left(a^{\prime \prime}\right)=$ $\tau\left(\mathrm{H}_{1}-\mathrm{O}_{2}-\mathrm{Si}_{3}-\mathrm{H}_{4}\right)$

$S_{11}\left(a^{\prime \prime}\right)=\quad \frac{1}{\sqrt{2}}\left[\angle\left(\mathrm{O}_{2}-\mathrm{Si}_{3}-\mathrm{H}_{5}\right)-\angle\left(\mathrm{O}_{2}-\mathrm{Si}_{3}-\mathrm{H}_{6}\right)\right]$

$S_{12}\left(a^{\prime \prime}\right)=\frac{1}{\sqrt{2}}\left[\tau\left(\mathrm{H}_{1}-\mathrm{O}_{2}-\mathrm{Si}_{3}-\mathrm{H}_{5}\right)+\tau\left(\mathrm{H}_{1}-\mathrm{O}_{2}-\mathrm{Si}_{3}-\mathrm{H}_{6}\right)\right]$

Following the computation of single point energies at each of these displaced geometries, the QFFs are generated by a least-squares fitting procedure where the sum of the squared residuals is on the order of $10^{-16}$ a.u. ${ }^{2}$ or less for all molecules. This yields the equilibrium geometry, and a refit of the potential energy surface zeros the gradients and produces the new equilibrium geometry along with the corresponding force constants. The resulting force constants are transformed into Cartesian coordinates using the INTDER program (Allen \& coworkers 2005) which are then used in second-order rotational and vibrational perturbation theory (Mills 1972) within the SPECTRO software package (Gaw et al. 1996) in order to calculate rovibrational spectral data (Watson 1977; Papousek \& Aliev 1982). Type-1 and 2 Fermi resonances, Fermi polyads (Martin \& Taylor 1997), Coriolis resonances, and Darling-Dennison resonances are taken into account to increase the accuracy of the rovibrational data (Martin et al. 1995; Martin \& Taylor 1997). The Fermi resonances for each molecule can be found in Table S2.

\section{RESULTS AND DISCUSSION}

\subsection{Geometries and rotational constants}

$\mathrm{AlH}_{3} \mathrm{OH}_{2}$ has the largest dipole moment out of the three molecules studied at $4.58 \mathrm{D}$. This dipole moment is stronger than other, similar aluminum and oxygen containing molecules such as $\mathrm{AlH}_{2} \mathrm{OH}$ and 
Table 1. Rotational constants and dipole moment of $\mathrm{AlH}_{3} \mathrm{OH}_{2}, \mathrm{SiH}_{3} \mathrm{NH}_{2}$, and $\mathrm{SiH}_{3} \mathrm{OH}$

\begin{tabular}{llrrr} 
Constant & Units & $\mathrm{AlH}_{3} \mathrm{OH}_{2}$ & $\mathrm{SiH}_{3} \mathrm{NH}_{2}$ & \multicolumn{1}{c}{$\mathrm{SiH}_{3} \mathrm{OH}$} \\
\hline$A_{0}$ & $\mathrm{MHz}$ & 56168.1 & 68818.9 & 77174.6 \\
$B_{0}$ & $\mathrm{MHz}$ & 9274.6 & 12646.5 & 13775.4 \\
$C_{0}$ & $\mathrm{MHz}$ & 9130.9 & 12224.7 & 13553.9 \\
\hline$\Delta_{J}$ & $\mathrm{kHz}$ & 23.495 & 11.122 & 13.574 \\
$\Delta_{K}$ & $\mathrm{kHz}$ & 165.768 & 359.365 & 463.425 \\
$\Delta_{J K}$ & $\mathrm{kHz}$ & 93.777 & 124.706 & 177.170 \\
$\delta_{J}$ & $\mathrm{~Hz}$ & 474.202 & 467.870 & 255.285 \\
$\delta_{K}$ & $\mathrm{kHz}$ & -544.657 & -307.033 & -658.864 \\
$\Phi_{J}$ & $\mathrm{mHz}$ & -91.250 & -2.035 & -2.752 \\
$\Phi_{K}$ & $\mathrm{~Hz}$ & 66.334 & 32.968 & 83.512 \\
$\Phi_{J K}$ & $\mathrm{~Hz}$ & 24.203 & 6.555 & 23.787 \\
$\Phi_{K J}$ & $\mathrm{~Hz}$ & -84.242 & -28.812 & -87.728 \\
$\phi_{j}$ & $\mu \mathrm{Hz}$ & -1768.830 & -418.967 & 613.039 \\
$\phi_{j k}$ & $\mathrm{~Hz}$ & -8.133 & -1.303 & -2.708 \\
$\phi_{k}$ & $\mathrm{kHz}$ & 6.367 & 0.951 & 4.257 \\
\hline$\mu$ & $\mathrm{D}$ & 4.58 & 1.21 & 1.29
\end{tabular}

Table 2. Vibrationally averaged and equilibrium geometrical parameters of $\mathrm{AlH}_{3} \mathrm{OH}_{2}$

\begin{tabular}{lrr} 
& Units & Value \\
\hline $\mathrm{R}_{0}\left(\mathrm{H}_{1}-\mathrm{Al}_{2}\right)$ & $\AA$ & 1.59197 \\
$\mathrm{R}_{0}\left(\mathrm{Al}_{2}-\mathrm{O}_{3}\right)$ & $\AA$ & 2.04014 \\
$\mathrm{R}_{0}\left(\mathrm{Al}_{2}-\mathrm{H}_{4}\right)$ & $\AA$ & 1.60154 \\
$\mathrm{R}_{0}\left(\mathrm{O}_{3}-\mathrm{H}_{6}\right)$ & $\AA$ & 0.91884 \\
$L_{0}\left(\mathrm{Al}_{2}-\mathrm{H}_{1}-\mathrm{O}_{3}\right)$ & $\operatorname{deg}$ & 101.834 \\
$\angle_{0}\left(\mathrm{Al}_{2}-\mathrm{H}_{5}-\mathrm{O}_{3}\right)$ & $\mathrm{deg}$ & 96.206 \\
$\angle_{0}\left(\mathrm{O}_{3}-\mathrm{H}_{6}-\mathrm{Al}_{2}\right)$ & $\mathrm{deg}$ & 116.385 \\
\hline $\mathrm{R}_{e}\left(\mathrm{H}_{1}-\mathrm{Al}_{2}\right)$ & $\AA$ & 1.58742 \\
$\mathrm{R}_{e}\left(\mathrm{Al}_{2}-\mathrm{O}_{3}\right)$ & $\AA$ & 2.02504 \\
$\mathrm{R}_{e}\left(\mathrm{Al}_{2}-\mathrm{H}_{4}\right)$ & $\AA$ & 1.59756 \\
$\mathrm{R}_{e}\left(\mathrm{O}_{3}-\mathrm{H}_{6}\right)$ & $\AA$ & 0.96189 \\
$L_{e}\left(\mathrm{Al}_{2}-\mathrm{H}_{1}-\mathrm{O}_{3}\right)$ & $\operatorname{deg}$ & 102.741 \\
$L_{e}\left(\mathrm{Al}_{2}-\mathrm{H}_{5}-\mathrm{O}_{3}\right)$ & $\operatorname{deg}$ & 95.695 \\
$L_{e}\left(\mathrm{O}_{3}-\mathrm{H}_{6}-\mathrm{Al}_{2}\right)$ & $\operatorname{deg}$ & 112.678
\end{tabular}

$\mathrm{AlOH}$ which have dipole moments of 1.22 and $1.11 \mathrm{D}$, respectively (Watrous et al. 2021; Fortenberry et al. 2020). $\mathrm{SiH}_{3} \mathrm{OH}$ has the second largest dipole at $1.29 \mathrm{D}$ which is much smaller than the dipole moment of $\mathrm{AlH}_{3} \mathrm{OH}_{2}$. $\mathrm{SiH}_{3} \mathrm{NH}_{2}$ has a slightly smaller dipole moment still than $\mathrm{SiH}_{3} \mathrm{OH}$ at 1.21 D. All three of these molecules have dipole moments large enough to be detectable in space through pure rotational spectroscopy, but $\mathrm{AlH}_{3} \mathrm{OH}_{2}$ does have a significantly larger dipole moment than the other two molecules. $\mathrm{AlH}_{3} \mathrm{OH}_{2}, \mathrm{SiH}_{3} \mathrm{OH}$, and $\mathrm{SiH}_{3} \mathrm{NH}_{2}$ all show near-prolate character as indicated by their $\kappa$ values of approximately -0.99 . Given this prolate nature, $\mathrm{SiH}_{3} \mathrm{OH}$ and $\mathrm{SiH}_{3} \mathrm{NH}_{2}$ could be expected to have $B_{\text {eff }}$ rotational constants comparable to their diatomic counterparts, $\mathrm{SiO}$ and $\mathrm{SiN}$. However, in actuality the addition of the hydrogen atoms causes the rotational constants nearly to halve relative to the isolated diatomics (Huber \& Herzberg 1979) and renders such a comparison moot. The principal rotational constants, quartic and sextic distortion coefficients, and dipole moments are reported in Table 1. The full set of equilibrium and first vibrationally excited rotational constants is shown in Table S1.

As shown in Table 2, $\mathrm{AlH}_{3} \mathrm{OH}_{2}$ has a heavy atom bond length of $2.03 \AA$. This is longer than the Al-O bond in $\mathrm{AlH}_{2} \mathrm{OH}$ and $\mathrm{AlOH}$ which are 1.70 and $1.68 \AA$, respectively (Watrous et al. 2021; Forten-
Table 3. Vibrationally averaged and equilibrium geometrical parameters of $\mathrm{SiH}_{3} \mathrm{OH}$

\begin{tabular}{lrr} 
& Units & Value \\
\hline $\mathrm{R}_{0}\left(\mathrm{H}_{1}-\mathrm{O}_{2}\right)$ & $\AA$ & 0.92024 \\
$\mathrm{R}_{0}\left(\mathrm{O}_{2}-\mathrm{Si}_{3}\right)$ & $\AA$ & 1.65312 \\
$\mathrm{R}_{0}\left(\mathrm{Si}_{3}-\mathrm{H}_{4}\right)$ & $\AA$ & 1.48371 \\
$\mathrm{R}_{0}\left(\mathrm{Si}_{3}-\mathrm{H}_{5}\right)$ & $\AA$ & 1.49070 \\
$\angle_{0}\left(\mathrm{O}_{2}-\mathrm{H}_{1}-\mathrm{Si}_{3}\right)$ & deg & 119.969 \\
$\angle_{0}\left(\mathrm{Si}_{3}-\mathrm{O}_{2}-\mathrm{H}_{4}\right)$ & deg & 106.489 \\
$\angle_{0}\left(\mathrm{Si}_{3}-\mathrm{O}_{2}-\mathrm{H}_{5}\right)$ & deg & 111.282 \\
\hline $\mathrm{R}_{e}\left(\mathrm{H}_{1}-\mathrm{O}_{2}\right)$ & $\AA$ & 0.95631 \\
$\mathrm{R}_{e}\left(\mathrm{O}_{2}-\mathrm{Si}_{3}\right)$ & $\AA$ & 1.64771 \\
$\mathrm{R}_{e}\left(\mathrm{Si}_{3}-\mathrm{H}_{4}\right)$ & $\AA$ & 1.47389 \\
$\mathrm{R}_{e}\left(\mathrm{Si}_{3}-\mathrm{H}_{5}\right)$ & $\AA$ & 1.48160 \\
$L_{e}\left(\mathrm{O}_{2}-\mathrm{H}_{1}-\mathrm{Si}_{3}\right)$ & $\operatorname{deg}$ & 118.225 \\
$\angle_{e}\left(\mathrm{Si}_{3}-\mathrm{O}_{2}-\mathrm{H}_{4}\right)$ & deg & 105.768 \\
$L_{e}\left(\mathrm{Si}_{3}-\mathrm{O}_{2}-\mathrm{H}_{5}\right)$ & deg & 111.547
\end{tabular}

Table 4. Vibrationally averaged and equilibrium geometrical parameters of $\mathrm{SiH}_{3} \mathrm{NH}_{2}$

\begin{tabular}{lrr} 
& Units & Value \\
\hline $\mathrm{R}_{0}\left(\mathrm{H}_{1}-\mathrm{Si}_{2}\right)$ & $\AA$ & 1.49434 \\
$\mathrm{R}_{0}\left(\mathrm{Si}_{2}-\mathrm{N}_{3}\right)$ & $\AA$ & 1.72495 \\
$\mathrm{R}_{0}\left(\mathrm{Si}_{2}-\mathrm{H}_{4}\right)$ & $\AA$ & 1.48713 \\
$\mathrm{R}_{0}\left(\mathrm{~N}_{3}-\mathrm{H}_{6}\right)$ & $\AA$ & 0.98636 \\
$\angle_{0}\left(\mathrm{Si}_{2}-\mathrm{H}_{1}-\mathrm{N}_{3}\right)$ & $\operatorname{deg}$ & 114.848 \\
$\angle_{0}\left(\mathrm{Si}_{2}-\mathrm{H}_{5}-\mathrm{N}_{3}\right)$ & $\operatorname{deg}$ & 108.286 \\
$\angle_{0}\left(\mathrm{~N}_{3}-\mathrm{H}_{6}-\mathrm{Si}_{2}\right)$ & $\operatorname{deg}$ & 121.756 \\
\hline $\mathrm{R}_{e}\left(\mathrm{H}_{1}-\mathrm{Si}_{2}\right)$ & $\AA$ & 1.48654 \\
$\mathrm{R}_{e}\left(\mathrm{Si}_{2}-\mathrm{N}_{3}\right)$ & $\AA$ & 1.72159 \\
$\mathrm{R}_{e}\left(\mathrm{Si}_{2}-\mathrm{H}_{4}\right)$ & $\AA$ & 1.47930 \\
$\mathrm{R}_{e}\left(\mathrm{~N}_{3}-\mathrm{H}_{6}\right)$ & $\AA$ & 1.00706 \\
$L_{e}\left(\mathrm{Si}_{2}-\mathrm{H}_{1}-\mathrm{N}_{3}\right)$ & $\operatorname{deg}$ & 115.666 \\
$L_{e}\left(\mathrm{Si}_{2}-\mathrm{H}_{5}-\mathrm{N}_{3}\right)$ & $\operatorname{deg}$ & 107.725 \\
$L_{e}\left(\mathrm{~N}_{3}-\mathrm{H}_{6}-\mathrm{Si}_{2}\right)$ & $\operatorname{deg}$ & 119.860
\end{tabular}

berry et al. 2020). In fact, this bond length is even longer than the 1.67 $\AA$ dative bond between $\mathrm{NH}_{3}$ and $\mathrm{BH}_{3}$ in ammonia borane (Thorne et al. 1983; Westbrook et al. 2021), suggesting that it also is dative in nature. $\mathrm{SiH}_{3} \mathrm{OH}$ has an $\mathrm{Si}-\mathrm{O}$ bond length of $1.65 \AA$ which is shorter than the Al-O bond length of $1.70 \AA$ in $\mathrm{AlH}_{2} \mathrm{OH}$ and the $\mathrm{Mg}-\mathrm{O}$ bond length of $1.77 \AA$ in $\mathrm{HMgOH}$ (Watrous et al. 2021). Despite the fact that Al-O has previously been reported to have a stronger bond than $\mathrm{Mg}-\mathrm{O}$ or Si-O, (Doerksen \& Fortenberry 2020) the slightly shorter bond length of $\mathrm{Si}-\mathrm{O}$ compared to $\mathrm{Al}-\mathrm{O}$ implies that $\mathrm{Si}-\mathrm{O}$ has a stronger bond in these molecules. However, this is a small difference and the bond lengths of $\mathrm{Si}-\mathrm{O}$ and $\mathrm{Al}-\mathrm{O}$ are close to the same value. In $\mathrm{SiH}_{3} \mathrm{NH}_{2}$, the $\mathrm{Si}-\mathrm{N}$ bond has a length of $1.74 \AA$ which is smaller than the $\mathrm{N}-\mathrm{Mg}$ bond length of $1.91 \AA$ in $\mathrm{HMgNH}_{2}$ and slightly smaller than the Al-N bond length of $1.78 \AA$ in $\mathrm{AlH}_{2} \mathrm{NH}_{2}$ (Watrous et al. 2021). Just like with the aforementioned $\mathrm{Si}-\mathrm{O}$ bond, the $\mathrm{Si}-\mathrm{N}$ bond is shorter than the previously studied Al-N even though earlier work shows that the Al-N bond is stronger than the $\mathrm{Si}-\mathrm{N}$ bond (Doerksen \& Fortenberry 2020).

\subsection{Vibrational Frequencies}

Over half of the double-harmonic MP2/aug-cc-pVTZ intensities for $\mathrm{AlH}_{3} \mathrm{OH}_{2}, \mathrm{SiH}_{3} \mathrm{OH}$, and $\mathrm{Si}_{3} \mathrm{NH}_{2}$ from Tables 5, 6, and 7 are on the same order or larger than the antisymmetric stretch in water, which 
Table 5. Vibrational Frequencies (in $\mathrm{cm}^{-1}$ ) of $\mathrm{AlH}_{3} \mathrm{OH}_{2}$ with MP2/aug-cc$\mathrm{pVTZ}$ Intensities in Parentheses (in $\mathrm{km} \mathrm{mol}^{-1}$ )

\begin{tabular}{llrr} 
& Description & Harmonic & Anharmonic \\
\hline$v_{1}\left(a^{\prime \prime}\right)$ & $1.001 S_{11}$ & $3900.9(142)$ & 3715.0 \\
$v_{2}\left(a^{\prime}\right)$ & $1.001 S_{4}$ & $3801.2(62)$ & 3624.5 \\
$v_{3}\left(a^{\prime}\right)$ & $0.952 S_{1}+0.049 S_{3}$ & $1920.4(168)$ & 1854.5 \\
$v_{4}\left(a^{\prime}\right)$ & $0.951 S_{3}-0.049 S_{1}$ & $1881.9(194)$ & 1819.3 \\
$v_{5}\left(a^{\prime \prime}\right)$ & $1.001 S_{10}$ & $1871.5(367)$ & 1809.0 \\
$v_{6}\left(a^{\prime}\right)$ & $0.622 S_{8}+0.386 S_{7}$ & $1649.2(91)$ & 1607.4 \\
$v_{7}\left(a^{\prime \prime}\right)$ & $0.555 S_{14}-0.394 S_{15}-0.053 S_{13}$ & $796.5(261)$ & 785.1 \\
$v_{8}\left(a^{\prime}\right)$ & $0.475 S_{9}-0.270 S_{6}-0.159 S_{8}-0.086 S_{5}$ & $794.2(297)$ & 778.9 \\
$v_{9}\left(a^{\prime}\right)$ & $0.461 S_{6}+0.349 S_{9}+0.186 S_{5}$ & $777.0(412)$ & 775.3 \\
$v_{10}\left(a^{\prime \prime}\right)$ & $0.548 S_{13}+0.430 S_{12}$ & $713.4(5)$ & 664.0 \\
$v_{11}\left(a^{\prime}\right)$ & $0.540 S_{5}+0.186 S_{7}-0.159 S_{6}-0.092 S_{9}$ & $523.4(153)$ & 487.9 \\
$v_{12}\left(a^{\prime}\right)$ & $0.430 S_{7}-0.192 S_{5}-0.176 S_{8}+0.116 S_{6}$ & $386.5(148)$ & 319.7 \\
$v_{13}\left(a^{\prime}\right)$ & $1.016 S_{2}$ & $372.6(23)$ & 350.6 \\
$v_{14}\left(a^{\prime \prime}\right)$ & $0.542 S_{12}-0.369 S_{13}-0.093 S_{14}$ & $366.0(5)$ & 364.1 \\
$v_{15}\left(a^{\prime \prime}\right)$ & $0.613 S_{15}+0.328 S_{14}$ & $94.7(37)$ & 225.8
\end{tabular}

Table 6. Vibrational Frequencies (in $\mathrm{cm}^{-1}$ ) of $\mathrm{SiH}_{3} \mathrm{OH}$ with MP2/aug-ccpVTZ Intensities in Parentheses (in $\mathrm{km} \mathrm{mol}^{-1}$ )

\begin{tabular}{llrr} 
& Description & Harmonic & Anharmonic \\
\hline$v_{1}\left(a^{\prime}\right)$ & $0.999 S_{1}$ & $3919.8(82)$ & 3742.9 \\
$v_{2}\left(a^{\prime}\right)$ & $1.000 S_{3}$ & $2286.9(103)$ & 2202.0 \\
$v_{3}\left(a^{\prime}\right)$ & $1.001 S_{4}$ & $2245.5(87)$ & 2167.4 \\
$v_{4}\left(a^{\prime \prime}\right)$ & $1.001 S_{9}$ & $2238.3(162)$ & 2159.1 \\
$v_{5}\left(a^{\prime}\right)$ & $0.722 S_{7}+0.192 S_{6}-0.047 S_{8}$ & $1007.8(183)$ & 990.6 \\
$v_{6}\left(a^{\prime}\right)$ & $0.865 S_{8}+0.065 S_{6}-0.049 S_{5}$ & $987.6(113)$ & 966.4 \\
$v_{7}\left(a^{\prime \prime}\right)$ & $0.665 S_{10}-0.304 S_{12}$ & $967.9(79)$ & 952.3 \\
$v_{8}\left(a^{\prime}\right)$ & $0.429 S_{2}+0.341 S_{5}+0.226 S_{6}$ & $911.2(70)$ & 889.9 \\
$v_{9}\left(a^{\prime}\right)$ & $0.521 S_{2}-0.314 S_{5}-0.094 S_{6}+0.069 S_{7}$ & $850.0(126)$ & 810.9 \\
$v_{10}\left(a^{\prime \prime}\right)$ & $0.961 S_{11}-0.046 S_{12}$ & $729.5(60)$ & 712.9 \\
$v_{11}\left(a^{\prime}\right)$ & $0.422 S_{6}-0.286 S_{5}-0.214 S_{7}-0.077 S_{8}$ & $690.1(58)$ & 683.3 \\
$v_{12}\left(a^{\prime \prime}\right)$ & $0.651 S_{12}+0.342 S_{10}$ & $196.2(93)$ & 181.1
\end{tabular}

has an intensity of roughly $70 \mathrm{~km} \mathrm{~mol}^{-1} \cdot \mathrm{AlH}_{3} \mathrm{OH}_{2}$, in particular, has four anharmonic frequencies with intensities over $200 \mathrm{~km} \mathrm{~mol}^{-1}, v_{5}$, $v_{7}, v_{8}$, and $v_{9}$ at $1809.0,785.1,778.9$, and $775.3 \mathrm{~cm}^{-1}$, respectively. These latter three are all within the $12-17 \mu \mathrm{m}$ region of the spectrum, making them particularly useful for potential detection of $\mathrm{AlH}_{3} \mathrm{OH}_{2}$ in this window. Further, of $\mathrm{AlH}_{3} \mathrm{OH}_{2}$ 's five additional frequencies over $100 \mathrm{~km} \mathrm{~mol}^{-1}, v_{11}$ is also close to this window with a frequency of $523.4 \mathrm{~cm}^{-1}$ or $19.11 \mu \mathrm{m}$.

The intense $v_{5}$ antisymmetric Al-H stretching frequency at 1809.0 $\mathrm{cm}^{-1}$ corresponds to $5.53 \mu \mathrm{m}$ which is in the range of the infrared typically associated with PAHs (Molster et al. 2001). This is quite a bit lower in frequency relative to the Ar matrix experimental value for the antisymmetric stretch of planar $\mathrm{AlH}_{3}$ at $1882.7 \mathrm{~cm}^{-1}$ (Kurth et al. 1993). Similarly, the observed value of the $\mathrm{AlH}_{3}$ umbrella motion at $697.6 \mathrm{~cm}^{-1}$ is substantially lower than that of the $v_{9} \mathrm{O}-\mathrm{Al}-\mathrm{H}$ bend in $\mathrm{AlH}_{3} \mathrm{OH}_{2}$ at $775.3 \mathrm{~cm}^{-1}$ due to the water molecule's inhibition of this motion. In contrast, the experimental frequency of the bend in $\mathrm{AlH}_{3}$ at $783.5 \mathrm{~cm}^{-1}$ compares very well to the $v_{8} \mathrm{H}-\mathrm{O}-\mathrm{Al}-\mathrm{H}$ torsion in $\mathrm{AlH}_{3} \mathrm{OH}_{2}$ which has a frequency of $778.9 \mathrm{~cm}^{-1}$ implying a slight red-shift of this motion upon complexation with water.

$\mathrm{SiH}_{3} \mathrm{OH}$ similarly has five anharmonic frequencies with intensities over $100 \mathrm{~km} \mathrm{~mol}^{-1}$. Two of these, $v_{2}$ and $v_{4}$, correspond to the symmetric and antisymmetric $\mathrm{Si}-\mathrm{H}$ stretches. These frequencies at 2202.0 and $2159.1 \mathrm{~cm}^{-1}$ are equivalent to 4.54 and $4.63 \mu \mathrm{m}$ respectively and are, again, at the end of the infrared spectrum typically associated with PAHs (Molster et al. 2001). Another frequency with a large intensity is $v_{9}$ with an intensity of $126 \mathrm{~km} \mathrm{~mol}^{-1}$ at 810.9 $\mathrm{cm}^{-1}$ or $12.33 \mu \mathrm{m}$. This frequency is mostly made of the $\mathrm{Si}-\mathrm{O}$ stretch and is just within the $12-17 \mu \mathrm{m}$ region of the spectrum, making it a prime target for detection of this molecule. $v_{10}$ and $v_{11}$ also fall within this region at 712.9 and $683.3 \mathrm{~cm}^{-1}$ or 14.03 and $14.63 \mu \mathrm{m}$
Table 7. Vibrational frequencies (in $\mathrm{cm}^{-1}$ ) of $\mathrm{SiH}_{3} \mathrm{NH}_{2}$ with MP2/aug-ccpVTZ intensities (in $\mathrm{km} \mathrm{mol}^{-1}$ ) in parentheses

\begin{tabular}{|c|c|c|c|c|}
\hline & Description & Harmonic & Anharmonic & Experiment $^{a}$ \\
\hline$v_{1}\left(a^{\prime \prime}\right)$ & $1.001 S_{11}$ & $3677.8(22)$ & 3515.3 & 3547 \\
\hline$v_{2}\left(a^{\prime}\right)$ & $1.000 S_{4}$ & $3584.8(15)$ & 3438.7 & 3445 \\
\hline$v_{3}\left(a^{\prime \prime}\right)$ & $1.001 S_{10}$ & $2258.0(141)$ & 2172.2 & \\
\hline$v_{4}\left(a^{\prime}\right)$ & $0.977 S_{3}$ & $2256.1(76)$ & $2174.5\}$ & 2172 \\
\hline$v_{5}\left(a^{\prime}\right)$ & $0.978 S_{1}$ & $2208.9(167)$ & 2132.5 & \\
\hline$v_{6}\left(a^{\prime}\right)$ & $0.783 S_{7}-0.218 S_{8}$ & $1598.0(29)$ & 1563.7 & 1564 \\
\hline$v_{7}\left(a^{\prime}\right)$ & $0.517 S_{6}+0.387 S_{5}+0.078 S_{9}$ & $1000.0(215)$ & $984.7)$ & 996 \\
\hline$v_{8}\left(a^{\prime \prime}\right)$ & $0.546 S_{14}-0.334 S_{15}-0.115 S_{12}$ & $997.5(65)$ & $976.0\}$ & 983 \\
\hline$v_{9}\left(a^{\prime}\right)$ & $0.903 S_{9}-0.107 S_{6}$ & $944.4(103)$ & 932.4 & 970 \\
\hline$v_{10}\left(a^{\prime \prime}\right)$ & $0.623 S_{13}-0.352 S_{12}$ & $921.1(40)$ & 885.8 & \\
\hline$v_{11}\left(a^{\prime}\right)$ & $0.938 S_{2}$ & $851.0(49)$ & 842.4 & 845 \\
\hline$v_{12}\left(a^{\prime}\right)$ & $0.612 S_{5}-0.346 S_{6}-0.072 S_{9}$ & $712.8(63)$ & 699.2 & $670^{b}$ \\
\hline$v_{13}\left(a^{\prime \prime}\right)$ & $0.495 S_{12}+0.368 S_{13}+0.152 S_{14}$ & $629.9(35)$ & 608.7 & $670^{b}$ \\
\hline$v_{14}\left(a^{\prime}\right)$ & $0.833 S_{8}+0.197 S_{7}+0.044 S_{9}$ & $393.4(153)$ & 244.2 & \\
\hline$v_{15}\left(a^{\prime \prime}\right)$ & $0.683 S_{15}+0.274 S_{14}$ & $177.5(13)$ & 242.8 & \\
\hline
\end{tabular}

respectively, although they have more modest intensities of 60 and 58 $\mathrm{km} \mathrm{mol}^{-1}$. Regardless, these frequencies may also help to elucidate the presence of $\mathrm{SiH}_{3} \mathrm{OH}$ in this spectral window.

The $\mathrm{SiH}_{3} \mathrm{OH}$ harmonic frequencies calculated in this work correspond well to previous $\operatorname{CCSD}(\mathrm{T}) / \mathrm{d}$-aug-cc-pVTZ results (NIST 2020), with the largest difference occurring in $\omega_{5}$ at just under 15 $\mathrm{cm}^{-1}$. However, the average magnitude of the deviation is only 5.1 $\mathrm{cm}^{-1}$. While there are no current experimental data for $\mathrm{SiH}_{3} \mathrm{OH}$, isovalent $\mathrm{CH}_{3} \mathrm{OH}$ is a well-known molecule in space (Ball et al. 1970; McGuire 2018) with comparable experimental data (Shimanouchi 1972). As such, the anharmonic frequencies of $\mathrm{CH}_{3} \mathrm{OH}$ are also calculated at the F12-TZ level to serve as an additional benchmark for the data generated for the other molecules in this work. Of the 10 available gas-phase frequencies, the largest deviation occurs in $v_{3}$ at a $-54.0 \mathrm{~cm}^{-1}$ difference between the experimental value of 2960 $\mathrm{cm}^{-1}$ and the $\mathrm{F} 12-\mathrm{TZ}$ result at $2906.0 \mathrm{~cm}^{-1}$. However, the computed $\mathrm{O}-\mathrm{H}$ stretch has a difference of only $0.8 \mathrm{~cm}^{-1}$ from the experimental data, and the average magnitude of the deviation is less than $10 \mathrm{~cm}^{-1}$. This good overall agreement suggests the performance of the same methodology should provide accurate predictions of the fundamental frequencies of $\mathrm{SiH}_{3} \mathrm{OH}$, as well.

Like $\mathrm{SiH}_{3} \mathrm{OH}, \mathrm{SiH}_{3} \mathrm{NH}_{2}$ has five anharmonic frequencies with intensities over $100 \mathrm{~km} \mathrm{~mol}^{-1}$. These are also the same types as the five most intense frequencies in $\mathrm{AlH}_{3} \mathrm{OH}_{2}$ : the three third-row atom hydride stretches and two bends. The $\mathrm{Si}-\mathrm{H}$ stretches fall just above the corresponding $\mathrm{Si}-\mathrm{H}$ stretches of $\mathrm{SiH}_{3} \mathrm{OH}$ at 4.60 and $4.69 \mu \mathrm{m}$ or 2174.5 and $2132.5 \mathrm{~cm}^{-1}$. Additionally, the $v_{14}$ torsional fundamental at $244.2 \mathrm{~cm}^{-1}$ or $40.95 \mu \mathrm{m}$ has an intensity of $153 \mathrm{~km} \mathrm{~mol}^{-1}$. This frequency is significantly farther out from the infrared spectrum than the other frequency that has been attributed to silicates between 2.4 and $12 \mu \mathrm{m}$ (Molster et al. 2001), offering a new region for detecting such molecules at THz frequencies. The picture within the 12-17 $\mu \mathrm{m}$ window is less vivid than for the other molecules, however. Only $v_{12}$ and $v_{13}$ fall directly within this region at 699.2 and $608.7 \mathrm{~cm}^{-1}$ or 14.30 and $16.43 \mu \mathrm{m}$, and they have fairly low intensities of 63 and $35 \mathrm{~km} \mathrm{~mol}^{-1} \cdot v_{11}$ also comes close to this window at $842.4 \mathrm{~cm}^{-1}$ or $11.87 \mu \mathrm{m}$, but it, too, has a modest intensity of only $49 \mathrm{~km} \mathrm{~mol}^{-1}$. Still, all of these frequencies may help to shed some light on this currently sparsely-identified region of the spectrum.

The $\mathrm{SiH}_{3} \mathrm{NH}_{2}$ vibrational frequencies reported in this paper compare well to the available experimental data from Beach (1992). In particular, the computed $v_{3}$ antisymmetric Si-H stretch at 2172.2 $\mathrm{cm}^{-1}$ is virtually identical to the gas-phase value of $2172 \mathrm{~cm}^{-1}$. However, the fairly broad peak in the experimental spectrum could 
also be attributed to $v_{4}$, the symmetric $\mathrm{Si}-\mathrm{H}$ stretch, or even $v_{5}$, the apical Si-H stretch, reported here to have very similar frequencies of 2174.5 and $2132.5 \mathrm{~cm}^{-1}$. The proximity of these three modes would require a much more high-resolution experiment to separate them, but our methods are giving unique identification for this spectral region for this molecule. Similarly, $v_{7}$ and $v_{8}$ are assigned as shoulders on the more prominent $v_{9}$ peak around $970 \mathrm{~cm}^{-1}$ in the experimental spectrum. In the same vein, the very broad peak centered around 670 $\mathrm{cm}^{-1}$ does not afford the opportunity to separate the distinct peaks reported here at 699.2 and $608.7 \mathrm{~cm}^{-1}$ for $v_{12}$ and $v_{13}$, respectively. In all of these cases, direct attribution of the experimental spectrum is currently impossible, but the F12-TZ values presented herein may help to identify the unique spectral features of these modes in future high-resolution experiments.

The related SiO (Wilson et al. 1971; Dickinson 1972) and $\mathrm{SiN}$ (Turner 1992) molecules are well known in the interstellar medium and potentially offer a point of comparison for the $\mathrm{Si}-\mathrm{O}$ stretch in $\mathrm{SiH}_{3} \mathrm{OH}$ and the $\mathrm{Si}-\mathrm{N}$ stretch in $\mathrm{SiH}_{3} \mathrm{NH}_{2}$. However, the $\mathrm{Si}-\mathrm{O}$ stretch computed herein for $\mathrm{SiH}_{3} \mathrm{OH}$ (again, $v_{9}$ ) is substantially red-shifted compared to the experimental value for $\mathrm{SiO}$ at $1229.6 \mathrm{~cm}^{-1}$ (Huber \& Herzberg 1979). Similarly, there is a large red-shift in the $\mathrm{Si}-\mathrm{N}$ stretch in $\mathrm{SiH}_{3} \mathrm{NH}_{2}$ at $842.4 \mathrm{~cm}^{-1}$ compared to the experimental value for isolated $\mathrm{SiN}$ at $1138.4 \mathrm{~cm}^{-1}$ (Huber \& Herzberg 1979). This suggests that even though the two pairs of molecules may be likely to occur in the same regions, they should have little spectral overlap. In fact, the closest $\mathrm{SiH}_{3} \mathrm{OH}$ frequency to the $\mathrm{SiO}$ stretch is $v_{5}$ at $990.6 \mathrm{~cm}^{-1}$, and the closest $\mathrm{SiH}_{3} \mathrm{NH}_{2}$ frequency to the $\mathrm{SiN}$ stretch is $v_{7}$ at 984.7 $\mathrm{cm}^{-1}$, allowing $\mathrm{SiH}_{3} \mathrm{OH}$ and $\mathrm{SiH}_{3} \mathrm{NH}_{2}$ to be easily disentangled spectroscopically from their related diatomic molecules, even if they are found in the same region. This is especially important for $\mathrm{SiH}_{3} \mathrm{OH}$ in the case that it has a similar reduction pathway as carbon monoxide does to methanol.

Finally, $v_{15}$ for $\mathrm{AlH}_{3} \mathrm{OH}_{2}$ and $\mathrm{SiH}_{3} \mathrm{NH}_{2}$ both have positive anharmonicities. In particular, $v_{15}$ of $\mathrm{AlH}_{3} \mathrm{OH}_{2}$ shows quite a large positive anharmonicity of $131.1 \mathrm{~cm}^{-1}$ above the harmonic frequency, yielding a fundamental frequency of $225.8 \mathrm{~cm}^{-1}$. The positive anharmonicity for $\mathrm{SiH}_{3} \mathrm{NH}_{2}$ is not as large with the anharmonic frequency at 242.8 $\mathrm{cm}^{-1}$ only $65.3 \mathrm{~cm}^{-1}$ above the harmonic frequency. While having such large positive anharmonicities raises questions about the reliability of the affected mode, it has been previously reported that near prolate molecules show positive anharmonicities in the smaller frequencies (McNavage et al. 2013; Fortenberry et al. 2012b,a; Huang et al. 2013; Watrous et al. 2021). These frequencies also have relatively small intensities, suggesting that they would be unhelpful for astronomical or laboratory detection anyway.

\section{CONCLUSIONS}

All three of the molecules examined in this work, $\mathrm{AlH}_{3} \mathrm{OH}_{2}$, $\mathrm{SiH}_{3} \mathrm{OH}$, and $\mathrm{SiH}_{3} \mathrm{NH}_{2}$, have substantial dipole moments that make them observable radioastronomically. In particular, $\mathrm{AlH}_{3} \mathrm{OH}_{2}$ has the largest dipole moment of the three at $4.58 \mathrm{D}$, while $\mathrm{SiH}_{3} \mathrm{OH}$ and $\mathrm{Si}_{3} \mathrm{NH}_{2}$ have smaller dipoles at 1.29 and $1.21 \mathrm{D}$ respectively. Each of these molecules also has at least five fundamental frequencies with large intensities greater than $100 \mathrm{~km} \mathrm{~mol}^{-1}$, making the readily visible to infrared spectroscopic investigation, such as that performed by JWST or by the ongoing SOFIA mission. Nearly all of these intense modes are within the spectral range of the high-resolution EXES instrument on SOFIA, making it a particularly appealing avenue for taking advantage of the data presented herein. Even more importantly, each of these molecules has at least two frequencies within the uncertain 12-17 $\mu \mathrm{m}$ spectral region, where identification may be particularly facile. For $\mathrm{SiH}_{3} \mathrm{NH}_{2}$ the frequencies in this region have intensities of only about $50 \mathrm{~km} \mathrm{~mol}^{-1}$, but $\mathrm{SiH}_{3} \mathrm{OH}$ has one frequency just inside this window at $12.33 \mu \mathrm{m}$ with a substantial intensity of $126 \mathrm{~km} \mathrm{~mol}^{-1}$. On the other hand, $\mathrm{AlH}_{3} \mathrm{OH}_{2}$ has three very intense frequencies in this region, with $v_{7}, v_{8}$, and $v_{9}$ all having intensities above $261 \mathrm{~km} \mathrm{~mol}^{-1}$, and $v_{9}$ in particular having an enormous intensity of $412 \mathrm{~km} \mathrm{~mol}^{-1}$. As such, $\mathrm{AlH}_{3} \mathrm{OH}_{2}$ may be particularly identifiable in this region.

Further, previous work has shown that $\mathrm{AlH}_{3} \mathrm{OH}_{2}$ is likely to be formed from reactions of water and the possible interstellar molecule of $\mathrm{AlH}_{3}$ and may also provide insight into the formation of inorganic oxides from simple metal hydrides and water (Swinnen et al. 2009). Hence, the spectral data reported here will help with possible detection of this molecule through rotational and infrared spectroscopy, especially given the very large intensities of many of its fundamental frequencies and the occurrence of these frequencies in a relatively unidentified spectral region. Such a detection would help to shed some light on the abundance of the rotationally-dark $\mathrm{AlH}_{3}$.

$\mathrm{SiH}_{3} \mathrm{OH}$ and $\mathrm{SiH}_{3} \mathrm{NH}_{2}$ are similar to $\mathrm{Al}$ and $\mathrm{Mg}$ compounds that have been studied previously, and they both have highly intense vibrational frequencies in their own rights. Namely, the Si-O stretch in $\mathrm{SiH}_{3} \mathrm{OH}$ at $850.0 \mathrm{~cm}^{-1}$ or $11.76 \mu \mathrm{m}$ has an intensity of $126 \mathrm{~km}$ $\mathrm{mol}^{-1}$, and the $\mathrm{Si}-\mathrm{H}$ stretches of $\mathrm{SiH}_{3} \mathrm{NH}_{2}$ have intensities of 141, 76 , and $167 \mathrm{~km} \mathrm{~mol}^{-1}$ at frequencies of 2258.0, 2256.1, and 2208.9 $\mathrm{cm}^{-1}$ or $4.429,4.432$, and $4.527 \mu \mathrm{m}$, respectively. Although these frequencies do not fall in the $12-17 \mu \mathrm{m}$ region like some of the slightly less intense frequencies for these molecules, they are still found in a region of the spectrum in which few molecules have currently been identified and those that have been elucidated are primarily carbonaceous molecules like PAHs. Hence, the present work may help to shed some light on new types of molecules that are waiting to be found in this region of the spectrum as well.

\section{ACKNOWLEDGEMENTS}

This work is made possible by NASA Grant NNX17AH15G, NSF Grant OIA-1757220, and the College of Liberal Arts at the University of Mississippi. The computational facilities were provided by the Mississippi Center for Supercomputer Research (MCSR).

\section{DATA AVAILABILITY}

Supplementary data are available at MNRAS online.

Table S1. CCSD(T)-F12b/cc-pVTZ-F12 equilibrium and first vibrationally-excited rotational constants for $\mathrm{AlH}_{3} \mathrm{OH}_{2}, \mathrm{SiH}_{3} \mathrm{NH}_{2}$, and $\mathrm{SiH}_{3} \mathrm{OH}$ (in $\mathrm{MHz}$ ).

Table S2. Fermi Resonances of $\mathrm{AlH}_{3} \mathrm{OH}_{2}, \mathrm{SiH}_{3} \mathrm{OH}$, and $\mathrm{SiH}_{3} \mathrm{NH}_{2}$.

\section{REFERENCES}

Adler T. B., Knizia G., Werner H.-J., 2007, J. Chem. Phys., 127, 221106 Agbaglo D., Fortenberry R. C., 2019a, Int. J. Quantum Chem., 119, e25899 Agbaglo D., Fortenberry R. C., 2019b, Chem. Phys. Lett., 734, 136720 Allen W. D., coworkers 2005

Ball J. A., Gottlieb C. A., Lilley A. E., Radford H. E., 1970, Astrophys. J. Lett., 162, L203

Beach D. B., 1992, Inorg. Chem., 31, 4174

Chubb K. L., Min M., Kawashima Y., Helling C., Waldmann I., 2020, Astronom. Astrophys., 639 
Crawford T. D., Schaefer III H. F., 2000, in Lipkowitz K. B., Boyd D. B., eds, , Vol. 14, Reviews in Computational Chemistry. Wiley, New York, pp 33-136

Dickinson D. F., 1972, Astrophys. J., 175, L43

Doerksen E. S., Fortenberry R. C., 2020, ACS Earth Space Chem., 4, 812

Fortenberry R. C., Lee T. J., 2019, Ann. Rep. Comput. Chem., 15, 173

Fortenberry R. C., Huang X., Francisco J. S., Crawford T. D., Lee T. J., 2012a, J. Phys. Chem. A., 116, 9582

Fortenberry R. C., Huang X., Francisco J. S., Crawford T. D., Lee T. J., 2012b, J. Chem. Phys., 136, 234309

Fortenberry R. C., Trabelsi T., Francisco J. S., 2020, J. Phys. Chem. A

Frisch M. J., et al., 2016, Gaussian 16 Revision C.01

Gaw J. F., Willets A., Green W. H., Handy N. C., 1996

Huang X., Fortenberry R. C., Lee T. J., 2013, J. Chem. Phys., 139, 084313

Huber K. P., Herzberg G., 1979, Constants of Diatomic Molecules. Springer Science+Business Media New York

Kendall R. A., Dunning T. H., Harrison R. J., 1992, J. Chem. Phys., 96, 6796

Knizia G., Adler T. B., Werner H.-J., 2009, J. Chem. Phys., 130, 054104

Kurth F. A., Eberlein R. A., Schnöckel H., Downs A. J., Pulham C. R., 1993, J. Chem. Soc., Chem. Commun., pp 1302-1304

Martin J. M. L., Taylor P. R., 1997, Spectrochim. Acta A, 53, 1039

Martin J. M. L., Lee T. J., Taylor P. R., François J.-P., 1995, J. Chem. Phys., 103,2589

McGuire B. A., 2018, Astrophys. J. Suppl. Ser., 239, 17

McGuire B. A., Burkhardt A. M., Kalenskii S., Shingledecker C. N., Remijan A. J., Herbst E., McCarthy M. C., 2018, Science, 359, 202

McNavage W., Wilhelm M. J., Dai H.-L., 2013, Chem. Phys., 422, 290

Mills I. M., 1972, in Rao K. N., Mathews C. W., eds, , Molecular Spectroscopy - Modern Research. Academic Press, New York, pp 115-140

Møller C., Plesset M. S., 1934, Phys. Rev., 46, 618

Molster F. J., et al., 2001, Astron. Astrophys., 372, 165

Molster F. J., Waters L. B. F. M., Tielens A. G. G. M., 2002, Astronom. Astrophys., 382, 222

NIST 2020, NIST Computational Chemistry Comparison and Benchmark Database

Papousek D., Aliev M. R., 1982, Molecular Vibration-Rotation Spectra. Elsevier, Amsterdam

Peterson K. A., Adler T. B., Werner H.-J., 2008, J. Chem. Phys., 128, 084102

Raghavachari K., Trucks G. W., Pople J. A., Replogle E., 1989, Chem. Phys. Lett., 158, 207

Savage B. D., Sembach K. R., 1996, Annu. Rev. Astron. Astrophys., 34, 279

Shavitt I., Bartlett R. J., 2009, Many-Body Methods in Chemistry and Physics: MBPT and Coupled-Cluster Theory. Cambridge University Press, Cambridge

Shimanouchi T., 1972, Tables of Molecular Vibrational Frequencies, 39th edn. Vol. 1, National Standards Reference Data System, Washington, DC

Swinnen S., Nguygen V. S., Sakai S., Nguyen M. T., 2009, Chem. Phys. Lett., 472,175

Takigawa A., Kamizuka T., Tachibana S., Yamamura I., 2017, Sci. Adv., 3

Tenenbaum E. D., Ziurys L. M., 2009, Astrophys. J., 693, L59

Tenenbaum E. D., Ziurys L. M., 2010, Astrophys. J., pp L93-L97

Thorne L. R., Suenram R. D., Lovas F. J., 1983, J. Chem. Phys., 78, 167

Turner B. E., 1992, Astrophys. J., 388, L35

Valencia E. M., Worth C. J., Fortenberry R. C., 2020, Mon. Not. Royal Astron. Soc., 492, 276

Watrous A. G., Davis M. C., Fortenberry R. C., 2021, Frontiers in Astronomy and Space Sciences, 8

Watson J. K. G., 1977, in During J. R., ed., , Vibrational Spectra and Structure. Elsevier, Amsterdam, pp 1-89

Werner H.-J., et al., 2015

Werner H.-J., et al., 2020

Westbrook B. R., Fortenberry R. C., 2020, J. Phys. Chem. A, 124, 3191

Westbrook B. R., Valencia E. M., Rushing S. C., Tschumper G. S., Fortenberry R. C., 2021, J. Chem. Phys., 154, 041104

Wilson R. W., Penzias A. A., Jefferts K. B., Kutner M., Thaddeus P., 1971, Astrophys. J., 167, L97

Yousaf K. E., Peterson K. A., 2008, J. Chem. Phys., 129, 184108

\section{REFERENCES}

Adler T. B., Knizia G., Werner H.-J., 2007, J. Chem. Phys., 127, 221106 Agbaglo D., Fortenberry R. C., 2019a, Int. J. Quantum Chem., 119, e25899

Agbaglo D., Fortenberry R. C., 2019b, Chem. Phys. Lett., 734, 136720

Allen W. D., coworkers 2005

Ball J. A., Gottlieb C. A., Lilley A. E., Radford H. E., 1970, Astrophys. J. Lett., 162, L203

Beach D. B., 1992, Inorg. Chem., 31, 4174

Chubb K. L., Min M., Kawashima Y., Helling C., Waldmann I., 2020, Astronom. Astrophys., 639

Crawford T. D., Schaefer III H. F., 2000, in Lipkowitz K. B., Boyd D. B., eds, , Vol. 14, Reviews in Computational Chemistry. Wiley, New York, pp 33-136

Dickinson D. F., 1972, Astrophys. J., 175, L43

Doerksen E. S., Fortenberry R. C., 2020, ACS Earth Space Chem., 4, 812

Fortenberry R. C., Lee T. J., 2019, Ann. Rep. Comput. Chem., 15, 173

Fortenberry R. C., Huang X., Francisco J. S., Crawford T. D., Lee T. J., 2012a, J. Phys. Chem. A., 116, 9582

Fortenberry R. C., Huang X., Francisco J. S., Crawford T. D., Lee T. J., 2012b, J. Chem. Phys., 136, 234309

Fortenberry R. C., Trabelsi T., Francisco J. S., 2020, J. Phys. Chem. A

Frisch M. J., et al., 2016, Gaussian 16 Revision C.01

Gaw J. F., Willets A., Green W. H., Handy N. C., 1996

Huang X., Fortenberry R. C., Lee T. J., 2013, J. Chem. Phys., 139, 084313

Huber K. P., Herzberg G., 1979, Constants of Diatomic Molecules. Springer Science+Business Media New York

Kendall R. A., Dunning T. H., Harrison R. J., 1992, J. Chem. Phys., 96, 6796

Knizia G., Adler T. B., Werner H.-J., 2009, J. Chem. Phys., 130, 054104

Kurth F. A., Eberlein R. A., Schnöckel H., Downs A. J., Pulham C. R., 1993, J. Chem. Soc., Chem. Commun., pp 1302-1304

Martin J. M. L., Taylor P. R., 1997, Spectrochim. Acta A, 53, 1039

Martin J. M. L., Lee T. J., Taylor P. R., François J.-P., 1995, J. Chem. Phys., 103,2589

McGuire B. A., 2018, Astrophys. J. Suppl. Ser., 239, 17

McGuire B. A., Burkhardt A. M., Kalenskii S., Shingledecker C. N., Remijan A. J., Herbst E., McCarthy M. C., 2018, Science, 359, 202

McNavage W., Wilhelm M. J., Dai H.-L., 2013, Chem. Phys., 422, 290

Mills I. M., 1972, in Rao K. N., Mathews C. W., eds, , Molecular Spectroscopy - Modern Research. Academic Press, New York, pp 115-140

Møller C., Plesset M. S., 1934, Phys. Rev., 46, 618

Molster F. J., et al., 2001, Astron. Astrophys., 372, 165

Molster F. J., Waters L. B. F. M., Tielens A. G. G. M., 2002, Astronom. Astrophys., 382, 222

NIST 2020, NIST Computational Chemistry Comparison and Benchmark Database

Papousek D., Aliev M. R., 1982, Molecular Vibration-Rotation Spectra. Elsevier, Amsterdam

Peterson K. A., Adler T. B., Werner H.-J., 2008, J. Chem. Phys., 128, 084102

Raghavachari K., Trucks G. W., Pople J. A., Replogle E., 1989, Chem. Phys. Lett., 158, 207

Savage B. D., Sembach K. R., 1996, Annu. Rev. Astron. Astrophys., 34, 279

Shavitt I., Bartlett R. J., 2009, Many-Body Methods in Chemistry and Physics: MBPT and Coupled-Cluster Theory. Cambridge University Press, Cambridge

Shimanouchi T., 1972, Tables of Molecular Vibrational Frequencies, 39th edn. Vol. 1, National Standards Reference Data System, Washington, DC

Swinnen S., Nguygen V. S., Sakai S., Nguyen M. T., 2009, Chem. Phys. Lett., 472,175

Takigawa A., Kamizuka T., Tachibana S., Yamamura I., 2017, Sci. Adv., 3

Tenenbaum E. D., Ziurys L. M., 2009, Astrophys. J., 693, L59

Tenenbaum E. D., Ziurys L. M., 2010, Astrophys. J., pp L93-L97

Thorne L. R., Suenram R. D., Lovas F. J., 1983, J. Chem. Phys., 78, 167

Turner B. E., 1992, Astrophys. J., 388, L35

Valencia E. M., Worth C. J., Fortenberry R. C., 2020, Mon. Not. Royal Astron. Soc., 492, 276

Watrous A. G., Davis M. C., Fortenberry R. C., 2021, Frontiers in Astronomy 


\section{A. G. Watrous et al.}

and Space Sciences, 8

Watson J. K. G., 1977, in During J. R., ed., , Vibrational Spectra and Structure.

Elsevier, Amsterdam, pp 1-89

Werner H.-J., et al., 2015

Werner H.-J., et al., 2020

Westbrook B. R., Fortenberry R. C., 2020, J. Phys. Chem. A, 124, 3191

Westbrook B. R., Valencia E. M., Rushing S. C., Tschumper G. S., Fortenberry R. C., 2021, J. Chem. Phys., 154, 041104

Wilson R. W., Penzias A. A., Jefferts K. B., Kutner M., Thaddeus P., 1971, Astrophys. J., 167, L97

Yousaf K. E., Peterson K. A., 2008, J. Chem. Phys., 129, 184108

This paper has been typeset from a $\mathrm{T}_{\mathrm{E}} \mathrm{X} / \mathrm{L} \mathrm{T} \mathrm{EX}$ file prepared by the author. 